\title{
TESTING HYPOTHESIZED EVOLUTIONARY SHIFTS TOWARD STRESS TOLERANCE IN HYBRID HELIANTHUS SPECIES
}

\author{
Larry C. Brouillette ${ }^{1,2,4}$, Maheteme Gebremedhin ${ }^{1}$, \\ David M. Rosenthal ${ }^{1,3}$, and Lisa A. Donovan ${ }^{1}$
}

\begin{abstract}
AвSTRACT.-We examined how plant traits related to growth and resource use have evolved during hybrid speciation and specialization into stressful habitats. Two desert sunflower species of homoploid hybrid origin are endemic to habitats with lower soil nutrient levels than those of their ancestral parent species. We hypothesized that the hybrid species would exhibit greater tolerance to low levels of soil nutrients than their parental species. The 2 hybrid species, Helianthus anomalus and H. deserticola, and their parental species, H. annuus and H. petiolaris, were compared for plant traits and growth through reproduction under 3 nutrient levels in a greenhouse study. An additional seedling study compared species for maximum seedling relative growth rate under optimum conditions. The hybrid species did have greater tolerance of nutrient limitation than the parental species, demonstrated by a resistance to change in stem height and diameter growth across treatments. A similar trend was observed in total biomass at final harvest. This ability to maintain growth may be partially explained by maintained investment in photosynthetic enzymes regardless of nutrient treatment. Though the hybrid species were more tolerant of nutrient stress, differences in the hybrid response to nutrient stress compared to the parental species' response were much smaller than expected from habitat comparisons. Helianthus anomalus has evolved a classic stress-tolerant phenotype, having long leaf lifespan, tough leaves, and slower early seedling relative growth rate. While both hybrid species have a conservative growth strategy, which confers greater stress tolerance than the parental species possess, functional trait differences among the hybrids suggest that the 2 species have experienced vastly different selective pressures.
\end{abstract}

Key words: Helianthus, nutrient stress, tolerance, plant trait evolution, relative growth rate, hybrid speciation.

Evolution of tolerance to stressful environments is a major area of ecological research with important applications to conservation biology and crop breeding (Wang et al. 2003). Many studies report correlations between plant functional traits and environmental parameters, but fall short of demonstrating that traits of interest were derived under a specific set of environmental conditions (Grime 1977). Organisms with known evolutionary relationships, such as hybrid species and their ancestral parents, can be used to make stronger inferences that certain plant functional traits are adaptive. In this study we use a hybrid system to examine how environmental pressures directed the evolution of tolerance and functional trait responses to nutrient stress.

We focus on 4 species of sunflower that occur in the Great Basin. Due to variation in climatic and edaphic conditions, the Great Basin contains a patchwork of habitats spanning broad ranges of water and nutrient levels
(Smith \& Nowak 1990, Comstock and Ehleringer 1992). Helianthus annuus is a widely distributed annual sunflower that occurs on mesic, clay-based soils in the western United States. Helianthus petiolaris has a more restricted distribution, occurring on relatively more xeric, sandy soils (Heiser 1947). These 2 species hybridized multiple times to produce 3 ancient homoploid hybrid species (Rieseberg 1991). Hybridization produced individuals with functional trait values outside the range of the parental species, potentially making hybrids suited for colonization of extreme habitats (Rieseberg et al. 2003, Rosenthal et al. 2005b).

We compare the parental Helianthus species to the 2 hybrid species, which occur on sandy, nutrient-poor soils in the Great Basin Desert. Helianthus anomalus is endemic to active sand dunes, which are very poor in fertility and organic content $\left(\mathrm{N} \sim 0.01 \%, \mathrm{P} \sim 0.4 \mathrm{mg} \cdot \mathrm{g}^{-1}\right.$, organic content $\sim 0.01 \%$; Rosenthal et al. $2005 \mathrm{a}$,

\footnotetext{
${ }^{1}$ Department of Plant Biology, University of Georgia, Athens, GA 30602

22502 Miller Plant Sciences, Athens, GA 30602.

${ }^{3}$ Department of Biology, Portland State University, Portland, OR 97207

4E-mail: beau@plantbio.uga.edu
} 
Ludwig et al. 2006). Helianthus deserticola occurs on stabilized sand dunes with higher fertility $\left(\mathrm{N} \sim 0.03 \%, \mathrm{P} \sim 0.4 \mathrm{mg} \cdot \mathrm{g}^{-1}\right.$, organic content $\sim 0.02 \%$ ) than the $H$. anomalus habitat, but lower fertility than the nearby habitats of both parental species $(\mathrm{N} \sim 0.6 \%, \mathrm{P} \sim 0.6$ $0.7 \mathrm{mg} \cdot \mathrm{g}^{-1}$, organic content $\sim 0.04 \%-0.05 \%$; Rosenthal et al. 2005a, Ludwig et al. 2006, L.A. Donovan unpublished data). Previous studies have pointed toward nutrient availability as an important selective pressure in the habitats of the hybrid species (Ludwig et al. 2004, Rosenthal et al. 2005a). However, this is the 1st study to examine differences in nutrient stress tolerance in the hybrid species relative to the parental species. We determine how functional trait values in the hybrid species have shifted as the species became established in and adapted to resource-poor habitats in the Great Basin Desert.

Because the hybrid species occur on nutrient-poor soil, we hypothesized that they would exhibit greater tolerance to soil nutrient limitations than the parental species. We define nutrient stress tolerance as the ability to resist change in plant growth or biomass accumulation when nutrients vary from optimum to limiting levels. We also expected pronounced plant traits associated with low-resource habitats in the hybrid species, compared to the parental species. Suites of plant functional traits such as increased root mass ratios, lowered tissue turnover rates, and decreased transpiration rates have been proposed as adaptations that allow plants to inhabit resource-poor habitats. These traits may come at a physiological cost, exhibited as lowered photosynthetic rates, decreased capacity for nutrient uptake, and/or reduction in maximum growth rate (Chapin et al. 1993). Variation in specific leaf area (SLA, leaf area per unit dry mass) may also be an important trait in stressful environments. Traits such as leaf lifespan, leaf longevity, and maximum photosynthetic rate are strongly correlated with SLA across plant functional groups (Reich et al. 1997).

In this study we experimentally compared the growth and performance responses of 2 hybrid Helianthus species to their ancestral parent species at different nutrient levels. We expected the hybrid species to exhibit greater tolerance to nutrient stress than their parental species. We also examined a suite of traits important in nutrient-poor habitats to iden- tify putative mechanisms of nutrient stress tolerance.

\section{Methods}

Seeds were collected in 2002 from a single natural population of each species and stored at $6^{\circ} \mathrm{C}$ until use. Seeds from $H$. annuus, $H$. anomalus, and $H$. deserticola were collected at the Little Sahara Recreational Area, Juab County, Utah, the only known place where all 3 species presently co-occur. Seeds from $H$. petiolaris were collected from the population used by Rieseberg et al. (2003) located 10 miles south of Page along Hwy 89, Coconino County, Arizona. For all germination experiments, seeds of all 4 species were cold stratified on moist filter paper for 4 weeks. Seeds were then removed from cold treatment, stored in the dark at room temperature overnight, and transferred to fresh filter paper in petri dishes. Petri dishes were placed under fluorescent lights $\left(\sim 115 \mu \mathrm{mol} \cdot \mathrm{m}^{-2} \mathrm{~s}^{-1}\right)$ with a 12-hour photoperiod.

\section{Nutrient Limitation Experiment}

The nutrient limitation experiment was a complete randomized block design, with 4 species, 3 nutrient treatments, 3 blocks, and 3 replicates per block, totaling 108 plants. Seedlings with 0-2 true leaves were transplanted into $25-\mathrm{cm}$ pots in the University of Georgia greenhouses on 17-19 March 2004. Pots contained sand and baked clay in a 3:1 mixture (Turface, Profile Products, Buffalo Grove, IL). The high, medium, and low nutrient treatments were $40 \mathrm{~g}, 4 \mathrm{~g}$, and $2 \mathrm{~g}$, respectively, of slow-release fertilizer with macro and micronutrients (Osmocote Plus, Scotts Co., Marysville, $\mathrm{OH}$ ) applied on 23 March to the upper $2 \mathrm{~cm}$ of the soil. Nutrient levels were chosen based on a preliminary experiment in which the 40-g and 4-g treatment were applied to all 4 species and a 2 -g treatment was applied to $H$. anomalus, which showed a significant decrease in biomass over the small change in nutrient levels. Plants were watered daily to maintain field capacity. Seven plants died from transplant shock and were excluded from all analyses.

We measured stem height 5 times during the experiment, starting on 23 March and continuing at approximately 3 -week intervals. 
Measurements for the last 3 dates included the diameter of the stem at soil level. We determined leaf lifetime by marking the most recently fully expanded mature leaf on 5 May and recording the date when $50 \%$ of the leaf turned brown. On 27 May each plant was sampled for mature leaf traits by harvesting the most recently expanded fully mature leaf in early morning when leaves were fully hydrated. Leaf area (LI-3100, LI-COR Inc., Lincoln, NE), wet weight, and dry weight were measured to estimate SLA and leaf succulence (Jennings 1976). On 9 June a fruit ripeness penetrometer was used to estimate leaf toughness on a mature leaf (McCormick Fruit Tech., Yakima, WA). Variability of individual measurements was large, so the mean of 5-7 measurements was the estimate of leaf toughness for the plant.

Gas exchange traits were measured on 5-6 July for a subset of the plants (4 replicates, 4 species, 2 treatments [high and low]) with a portable gas exchange system (LI-6400, LICOR, Inc., Lincoln, NE). Inside the chamber, photosynthetically active radiation equalled $2000 \mu \mathrm{mol} \cdot \mathrm{m}^{-2} \mathrm{~s}^{-1}$ and air temperature was $\sim 30^{\circ} \mathrm{C}$. Measurements were taken at multiple external $\mathrm{CO}_{2}$ concentrations $\left(c_{a}\right)$ to determine rates of photosynthesis $(A)$ over a range of internal leaf $\mathrm{CO}_{2}$ concentrations $\left(c_{i}\right)$. In order, measurements were taken at $c_{a}$ equal to 400 , $300,200,100,50$, and $400 \mathrm{ppm}$. At low $c_{i}$, the relationship between photosynthetic rate and $c_{i}$ may be approximated by a straight line, the slope of which is proportional to investment in rubisco. We estimated investment in rubisco using the slope of a linear regression of $\mathrm{A}$ with $c_{i}$ when $c_{a}$ was set to the values stated above. We averaged the 2 measurements at $400 \mathrm{ppm}$ to estimate maximum photosynthesis $\left(A_{\max }\right)$. Date had no significant effect on measurements $(P>0.90)$ and was excluded from the final model. All measurements were corrected for leaf area (LI-3100).

Gas exchange leaves were individually dried at $60^{\circ} \mathrm{C}$, ground, and analyzed for $\mathrm{N}$ concentration (mg N $\cdot \mathrm{g}^{-1}$; Carbo Erba NA 1500) and leaf carbon isotopic composition (leaf $\delta^{13} \mathrm{C}$; Finnegan, continuous flow mass spectrometer, Bremen, Germany). Leaf $\delta^{13} \mathrm{C}$ provides an integrated measure of $c_{i}$ over the lifetime of the leaf. Integrated $c_{i}$ is, in turn, a relative measure of integrated water use efficiency (WUE), if leaf temperatures are similar (Farquhar et al.
1989, Ehleringer et al. 1992). A higher (less negative) leaf $\delta^{13} \mathrm{C}$ reflects greater WUE. Maximum photosynthetic rate, leaf $\mathrm{N}$, and specific leaf area were used to calculate photosynthetic nitrogen-use efficiency (PNUE) following Field and Mooney (1986).

All plants were harvested on 15-16 June. Biomass was partitioned into belowground, vegetative, and reproductive components. Counts were taken of number of buds, flowers, and seed heads to estimate life history stage at harvest. Biomass components were dried at $60^{\circ} \mathrm{C}$ and weighed.

We modeled each variable as a function of categorical variables in a mixed model ANOVA (PROC MIXED, SAS Institute, Cary, NC): treatment, species, treatment $\times$ species interaction, with block as a random effect. All biomass components were log-transformed to fit ANOVA assumptions. Visual inspection of residual plots revealed extreme outliers for leaf succulence $(n=2)$, specific leaf area $(n=2)$, total biomass $(n=1)$, and stem growth $(n=1)$. These observations were excluded from our analyses. Unadjusted values from the final 3 measurements of stem height and stem diameter were analyzed in a repeated-measures mixed model in PROC MIXED with an AR(1) covariance matrix. We used only the final 3 measurements because they were available for both growth measurements. Inclusion of stem height for the first 2 dates did not change the conclusions of statistical tests. For traits measured in all treatments, we separated the interaction term into 6 components: linear and quadratic trends between and within the hybrid and parental species (SAS CONTRAST statement). Partitioning the interaction term between hybrid and parental species tested the hypothesis that parental species respond differently to nutrient stress than hybrid species. Further separating the interaction into "within hybrids" and "within parentals" tested for species differences in response. For traits assessed only in high and low treatments, only linear components were examined. Evaluating these a priori comparisons retained precision that is lost in post hoc tests.

\section{Seedling Relative Growth Rate Experiment}

The relative growth rate study was a completely randomized design with 4 species, 2 harvests, and 12 replicates, giving a sample 
size of 96. On 17-19 March, seedlings were transplanted into $6.5 \mathrm{~cm} \times 25$-cm pots (Deepots, Stuewe \& Sons, Corvaillis, OR) containing the same soil mixture described for the nutrient limitation experiment. Seedlings were watered to field capacity daily and received nonlimiting nutrient solution weekly (300 ppm Pete Lite, J.R. Peters Laboratory, Allentown, PA). The plants were used to estimate maximum early seedling relative growth rate $\left(\mathrm{RGR}_{\max }\right)$ under optimum conditions for each of the 4 species. Plants were harvested on 29 March and $12 \mathrm{April}$, dried at $60^{\circ} \mathrm{C}$, and measured for total biomass. Log-transformed total biomass was regressed against harvest date, species, and their interaction (SAS PROC GLM; Poorter and Lewis 1986). We used Fisher's protected least significant difference tests to detect significant differences in the interaction term, indicating species with statistical differences in $\mathrm{RGR}_{\text {max }}$.

\section{RESUlTS}

\section{Nutrient Limitation Experiment}

Plant performance was assessed as stem growth (in height and diameter) and total biomass at harvest. All 4 species showed substantial reduction in growth and biomass production in response to lowered nutrient levels (Figs. 1, 2, Table 1). Hybrid species had a less drastic reduction in stem height and diameter growth than the parental species when we compared the low nutrient treatment to the high nutrient treatment. The effect was seen as a significant difference in linear response of hybrid and parental species (Table 1). This was paralleled by a similar, but not significant, pattern in total biomass (Fig. 1, Table 1; $F=0.14$ ). Individuals of the hybrid species under low nutrient treatment produced approximately $85 \%$ less biomass than those under high nutrient treatment. By comparison, parental species showed a $90 \%$ reduction. We used percentage of inflorescences at the seed-head stage to assess life history status. These data suggest differences in life history stage between species and treatments at harvest, with $H$. anomalus in the high treatment having the lowest percentage of inflorescences at the seed-head stage (Table 2).

There was a highly significant effect of treatment on leaf percent nitrogen, indicating
Total biomass at reproductive maturity

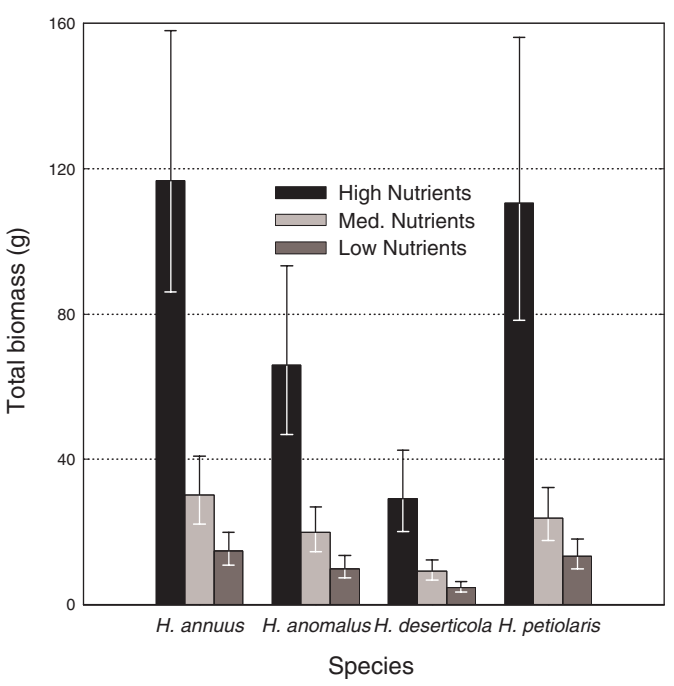

Fig. 1. Mean total biomass measurements and $95 \%$ confidence intervals for 4 Helianthus species grown in a greenhouse at 3 nutrient levels $(n=101)$.

that foliar nitrogen concentration paralleled soil nutrient levels. Hybrid species tended to have a smaller difference between treatments than parental species (Table 3). The opposite was true of leaf $\delta^{13} \mathrm{C}$, with parental species overall having less of a change in WUE as a response to treatment than hybrid species (Table $3 ; F=2.93, P \leq 0.10)$. There was also a difference between hybrid and parental species' responses to nutrient stress for leaf succulence; hybrid species tended to maintain higher leaf succulence under low nutrients (Table $2 ; F=$ 3.93, $P \leq 0.10)$. Hybrid species maintained higher investment in rubisco than parental species under low nutrient conditions, as seen in the significant difference in linear response of the initial slope of the $A / c_{i}$ curve (Fig. 3, Table $4 ; F=4.36, P \leq 0.05)$. Even though we examined $A_{\max }$ and leaf-level PNUE, only marginally significant differences in the linear response of hybrid and parental species were detected for $A_{\max }$ (Table $3 ; F=3.31, P \leq 0.10$ ).

In addition to the anticipated differences between the hybrid and parental species, the 2 hybrid species responded differently to nutrient treatment. Helianthus anomalus produced leaves that were tougher than those of the other species (Fig. 3, Table 4; $F=94.82$, $P \leq 0.0001)$. Additionally, $H$. anomalus produced longer-lived leaves in response to the lowered 


\section{Plant height and stem diameter growth}
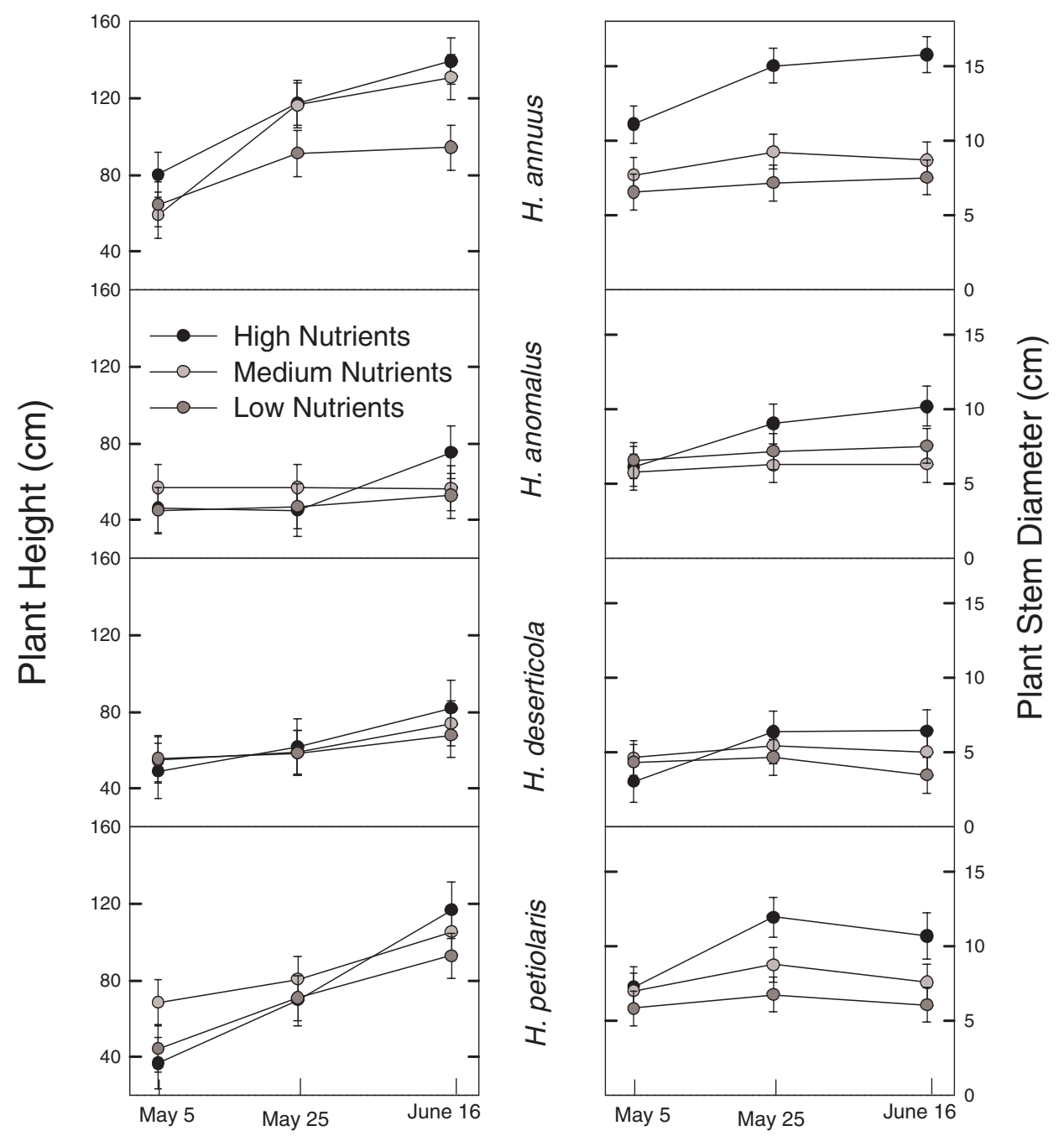

Date

Fig. 2. Stem height and diameter for 4 Helianthus species grown under 3 nutrient levels in a greenhouse $(n=101)$. Plotted values are arithmetic means at each date for each species-treatment combination. Least squared estimates of the means are given for each of 3 dates used in the repeated measures analysis. Measurements were repeated over all individual plants in the experiment at each time increment. Error bars represent $95 \%$ confidence intervals.

nutrients, assessed as a difference in linear nutrient stress response between $H$. anomalus and H. deserticola (Fig. 3, Table 4; $F=9.31, P \leq$ $0.01)$. We also observed a marginally significant quadratic response of $H$. anomalus root mass ratio to the treatment levels, suggesting a lower threshold for stress-induced root allocation (Table 2; $F=3.43, P \leq 0.10$ ).
Under low resources, $H$. deserticola had a mean maximum photosynthetic rate comparable to high nutrient plants, but the response of the 2 hybrid species was not significantly different (Table 3; $F=1$ ). Additionally, the linear response of specific leaf area to the nutrient levels in $H$. deserticola indicates that it produces thicker leaves in response to nutrient 
TABLe 1. Analysis of plant growth variables and total biomass. Degrees of freedom and $F$-values for the appropriate mixed model analysis of our 3 measures of tolerance: height growth, stem diameter growth, and total biomass at harvest $(n=101)$. Significant $F$-values are denoted as follows: $+(P \leq 0.10), *(P \leq 0.05), * *(P \leq 0.01)$, and *** $(P \leq 0.0001)$.

\begin{tabular}{|c|c|c|c|c|c|c|}
\hline \multirow[b]{2}{*}{ Source } & \multicolumn{2}{|c|}{ Height growth } & \multicolumn{2}{|c|}{ Stem diameter growth } & \multicolumn{2}{|c|}{ Total biomass } \\
\hline & $\mathrm{df}$ & $F$ & $\mathrm{df}$ & $F$ & $\mathrm{df}$ & F \\
\hline Species & 3,264 & $94.67 * * *$ & 3,260 & $122.66 * * *$ & 3,85 & $41.79 * * *$ \\
\hline Treatment & 2,264 & $13.38 * * *$ & 2,260 & $118.00^{* * * *}$ & 2,85 & $284.81^{* * * *}$ \\
\hline Species $\times$ Treatment & 6,264 & $3.58 * *$ & 6,260 & $14.63^{* * * *}$ & 6,85 & 0.68 \\
\hline Time & 2,264 & $95.83^{* * *} *$ & 2,260 & $29.38 * * *$ & & \\
\hline Species $\times$ Time & 6,264 & $11.47^{* * * *}$ & 6,260 & 0.9 & & \\
\hline Treatment $\times$ Time & 4,264 & $4.63^{* *}$ & 4,260 & $11.25^{* * * *}$ & & \\
\hline Species $\times$ Treatment $\times$ Time & 12,264 & $1.60+$ & 12,260 & 0.22 & & \\
\hline Linear parental $\times$ hybrid & 1,264 & $4.91 *$ & 1,260 & $30.32 * * *$ & 1,85 & 0.14 \\
\hline Linear annuus $\times$ petiolaris & 1,264 & $10.84^{* * *}$ & 1,260 & $25.15^{* * * *}$ & 1,85 & 0.04 \\
\hline Linear anomalus $\times$ deserticola & 1,264 & 0.23 & 1,260 & $13.56^{* * * *}$ & 1,85 & 1.12 \\
\hline Quadratic parental $\times$ hybrid & 1,264 & 1.99 & 1,260 & $5.73^{*}$ & 1,85 & 1.78 \\
\hline Quadratic annuus $\times$ petiolaris & 1,264 & 2.03 & 1,260 & $10.34^{* *}$ & 1,85 & 0.65 \\
\hline Quadratic anomalus $\times$ deserticola & 1,264 & 0.61 & 1,260 & 1.96 & 1,85 & 0.23 \\
\hline
\end{tabular}

stress, unlike the other study species (Fig. 3, Table $4 ; F=5.90, P \leq 0.05)$.

\section{Seedling Relative Growth Rate Experiment}

Helianthus anomalus had a significantly slower early seedling $\mathrm{RGR}_{\max }$ than $H$. deserticola and $H$. petiolaris. We estimated seedling $\mathrm{RGR}_{\max }$ for H. anomalus to be lower than that of $H$. annuus, but the difference was not significant (Fig. 4).

\section{Discussion}

We conclude that the hybrid species are more tolerant of nutrient stress than their parental species. We observed significant differences in stem height and diameter growth that suggested higher stress tolerance in the hybrid species. A similar trend was seen in total biomass, but differences were not significant. We found evidence that hybrid species have higher tolerance of nutrient limitation, but differences were much subtler than expected. The final harvest date arbitrarily truncated the life cycles of the species, and the failure to detect expected differences in biomass could be due to early cutoff of $H$. anomalus, which tends to persist in the field until 1st frost in many populations. A better test of the effects of nutrient limitation on fitness would have been a direct measure of seed set. Pollinators are excluded from the greenhouse, so seed weight and number are impossible to obtain without frequent crossing throughout the experiment.

Foliar nitrogen concentration was less responsive to treatment in hybrid species compared to parental species. This seems to be important in the field because selection analyses show a strong association between foliar nitrogen content and fitness in the H. anomalus habitat (Ludwig et al. 2004). High levels of foliar nitrogen may account for the greater investment in rubisco and marginally higher ability to maintain $A_{\max }$ found in hybrid species under low nutrient conditions. The resistance to changing investment in photosynthesis despite lower nitrogen availability is one possible explanation for increased nutrient stress tolerance of the hybrid species. Under low nutrient conditions, hybrid species also tended to have higher water-use efficiency and leaf succulence, which are putative drought resistance traits. Water does not appear to be a major limiting factor for $H$. anomalus in its home habitat, so drought-resistance traits in H. anomalus may result from genetic correlations among stress-resistance traits (Chapin et al. 1993).

Helianthus anomalus produced tougher, longer-lived leaves than the other species and showed a reduced early seedling RGR $_{\max }$. While RGR $_{\max }$ was not significantly lower than both parentals in this study, a subsequent experiment showed that $H$. anomalus had a significantly lower $\mathrm{RGR}_{\max }$ than $H$. annuus (data not shown). Helianthus anomalus also tended 


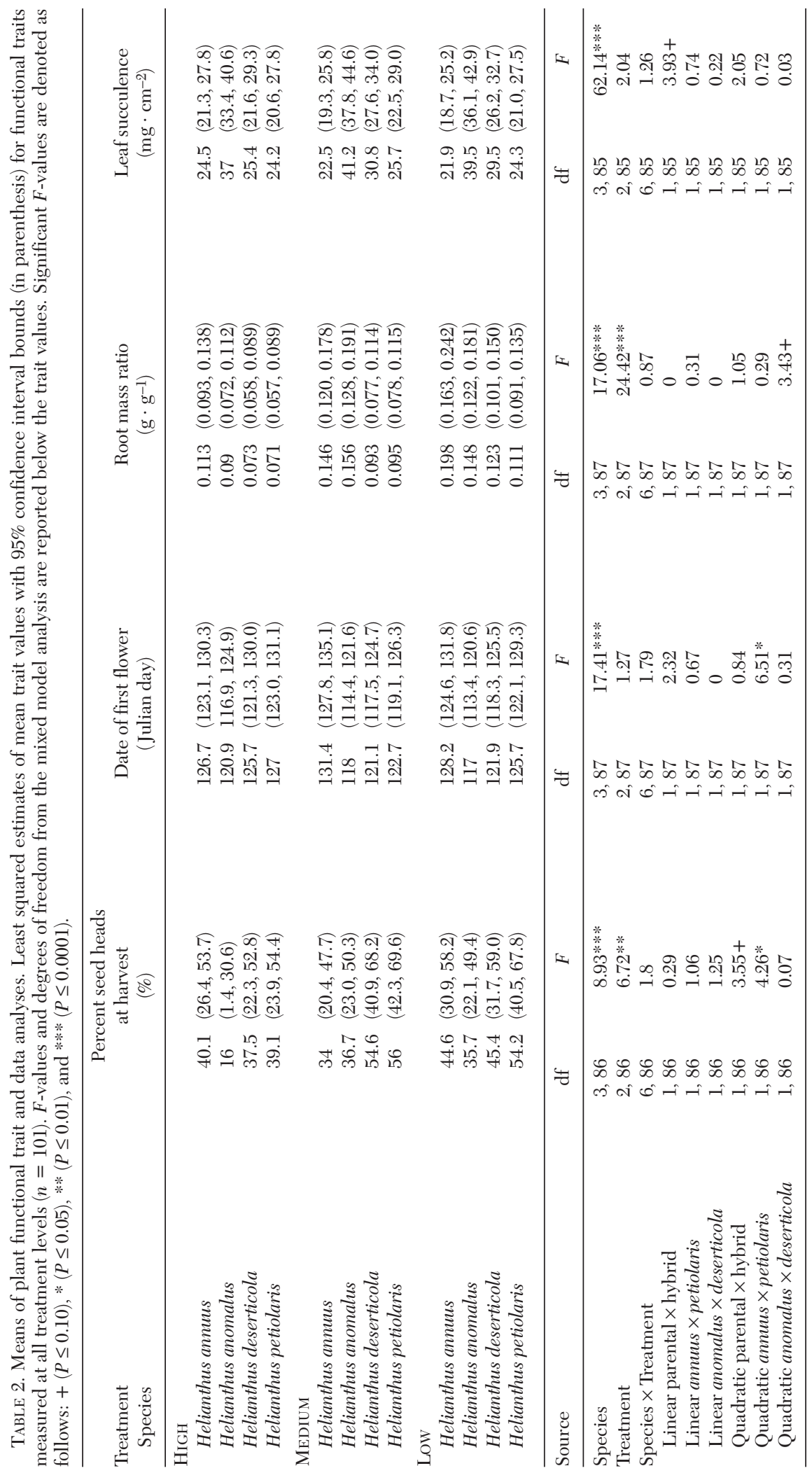



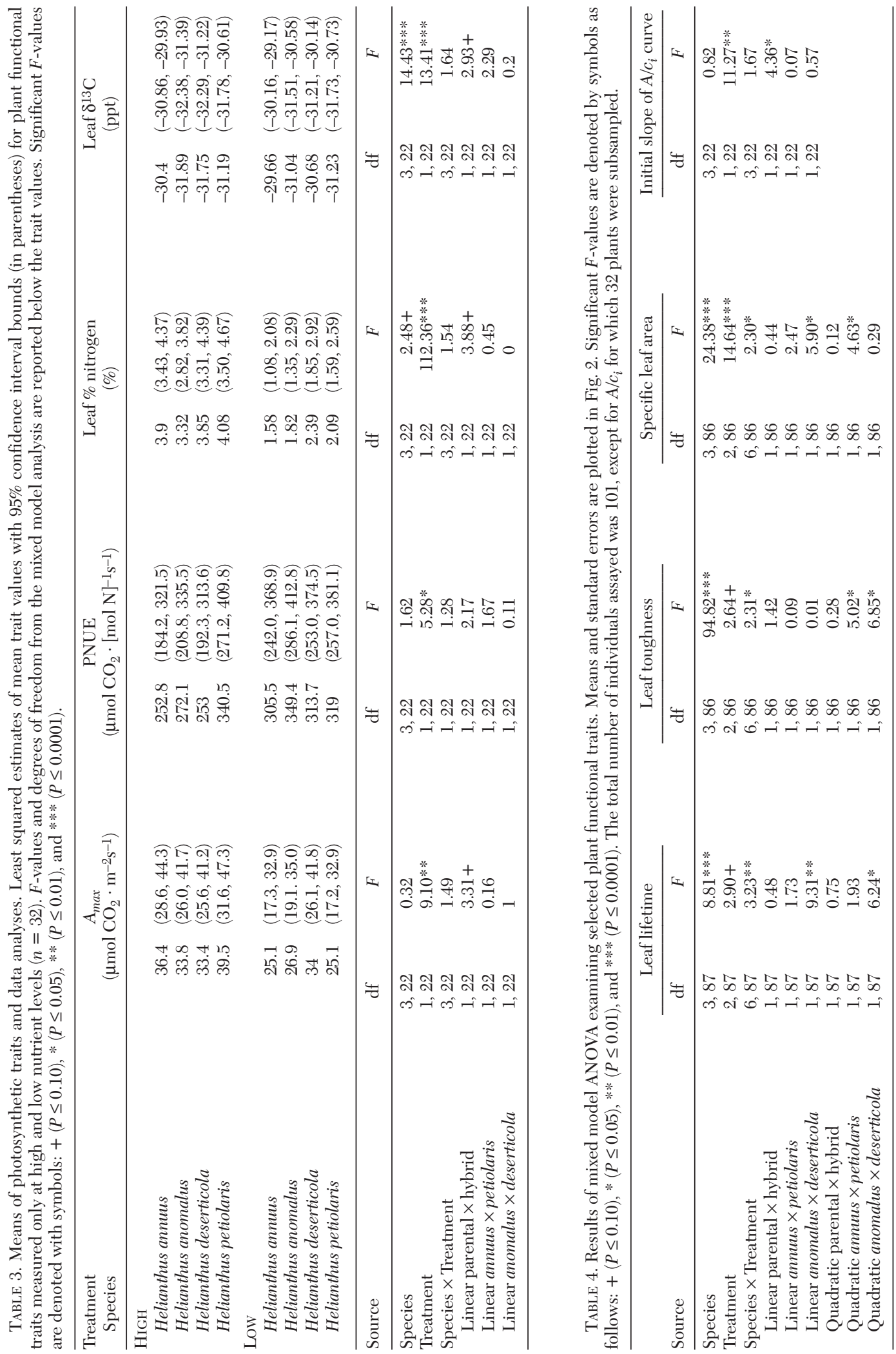


\section{Plant functional traits}
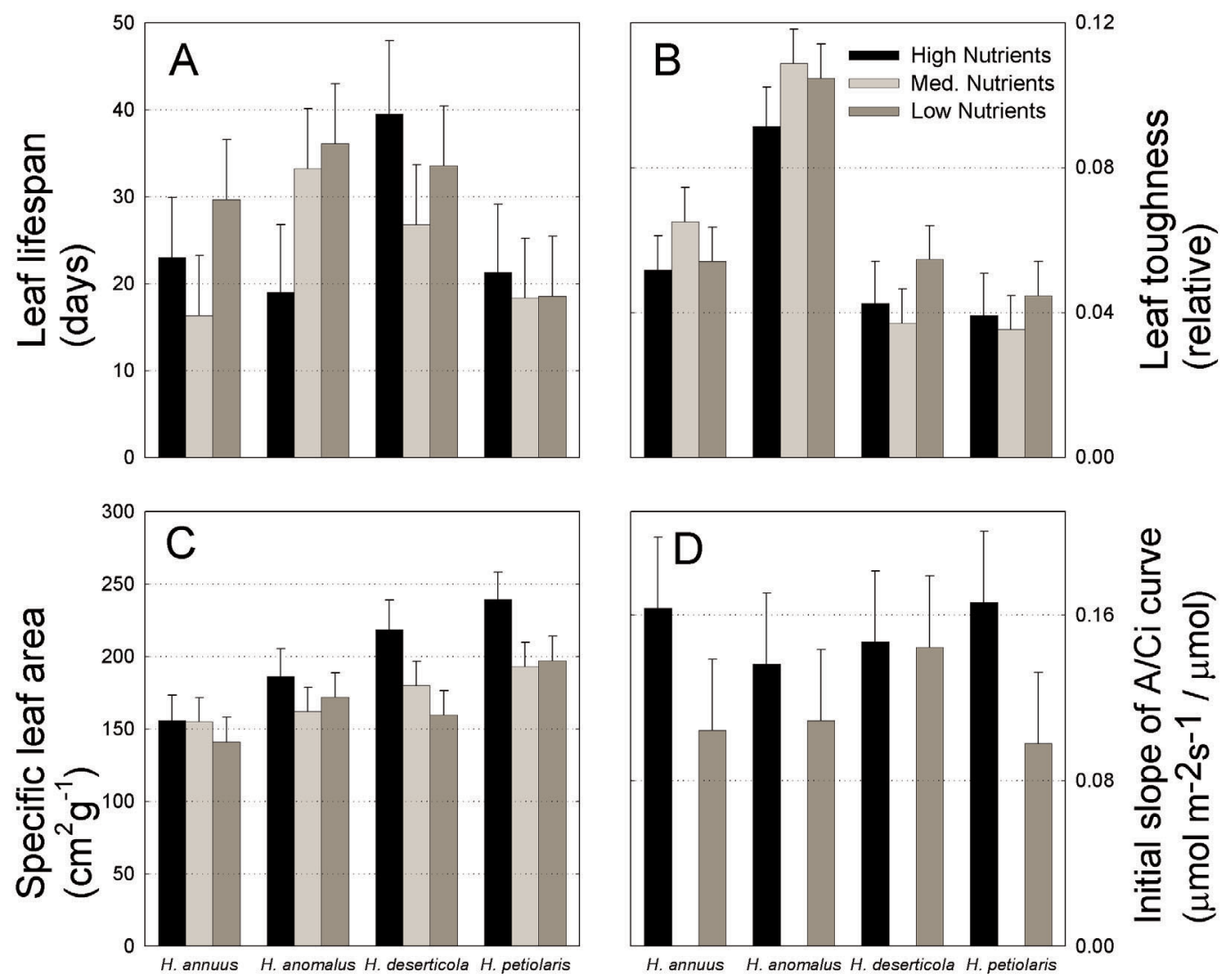

\section{Species}

Fig. 3. Model least squared estimates of the means of plant functional traits: (A) leaf lifespan, (B) leaf toughness, (C) specific leaf area, and (D) initial slope of $A / c_{i}$ curve. Traits were measured on 4 Helianthus species grown in a greenhouse under 3 nutrient levels. The total number of individuals assayed was 101, except for $A / c_{i}$ where 32 plants were subsampled. For gas exchange measurements, such as initial slope of $A / c_{i}$ curve, we subsampled individuals from high and low nutrient levels. Error bars represent $95 \%$ confidence intervals.

to increase investment in roots in the intermediate nutrient treatment. These observations suggest that $H$. anomalus has a classic stresstolerant phenotype. Under this paradigm, long leaf lifespan decreases demand and higher root allocation increases uptake of the limiting resource. These traits probably come at a cost of reduced seedling $\mathrm{RGR}_{\max }$ (Chapin et al. 1993).

Our data suggest that $H$. deserticola has a different strategy than $H$. anomalus. Unlike in $H$. anomalus habitat, water becomes scarce in $H$. deserticola habitat early in the growing season (Rosenthal et al. 2005a). Water and nutrients likely co-limit growth in $H$. deserticola habitat, imposing selective pressures different from those in $H$. anomalus habitat (Ludwig et al. 2004). Under low nutrients, H. deserticola produced leaves with low SLA, a trait correlated to putative adaptations to multiple abiotic stresses (Riech et al. 1997). It is also interesting that some photosynthetic traits were unresponsive to treatment in hybrids because we have observed unexpectedly high photosynthetic rates in $H$. deserticola growing in its nutrient-poor home habitat (D.M. Rosenthal unpublished data).

Though we initially expected more obvious differences, we demonstrate that $H$. anomalus 


\section{Maximum early seedling relative growth rate}

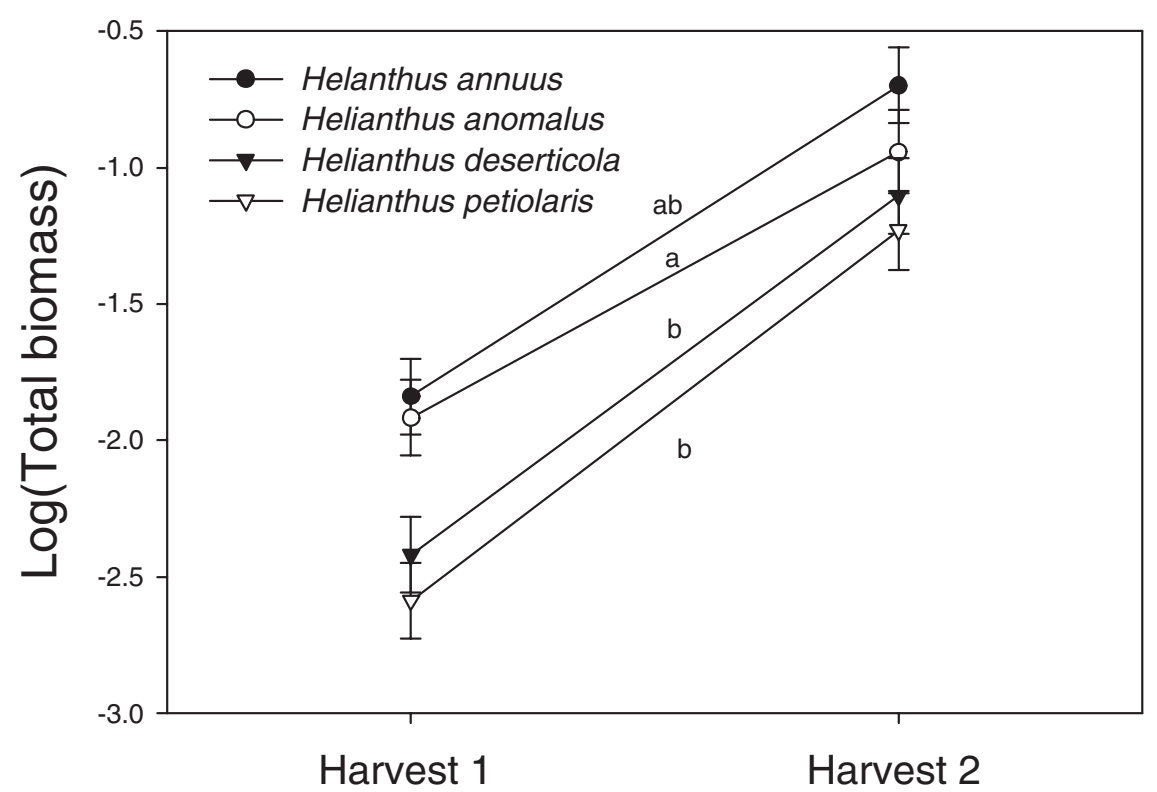

Fig. 4. LS means of log-transformed total seedling biomass plotted for 2 harvests and 4 species $(n=96)$. Slopes with the same letter are not significantly different, indicating that corresponding species have indistinguishable early seeding RGR at the $P=0.05$ level. Error bars represent $95 \%$ confidence intervals.

and $H$. deserticola are more tolerant of nutrient stress than their parental species. Additionally, we report shifts in the means of $H$. anomalus traits predicted by correlational studies of plant adaptations to abiotic stress. Helianthus anomalus also has a reduced seedling $\mathrm{RGR}_{\max }$, which is likely a physiological cost of stress resistance. Helianthus deserticola appears to acclimate to stress by shifting specific leaf area. Hybrid species maintain greater investment in photosynthetic enzymes despite severe nutrient limitation. While the 2 species exhibit similar growth responses to nutrient stress, $H$. anomalus and $H$. deserticola appear to have evolved different suites of traits to adapt to distinct low resource habitats.

\section{ACKNOWLEDGMENTS}

We thank A. Howard, C. Gormally, and 2 anonymous reviewers for comments on earlier drafts. Research was supported by NSF grant IBN-0131078 to L.A. Donovan and a UGA Plant Biology Department small grant to L.C. Brouillette.

\section{Literature Cited}

Chapin, F.S., K. Autumn, and F. Pugmaire. 1993. Evolution of suites of traits in response to stressful environments. American Naturalist 142:S78-S92.

Comstock, J.P., AND J.R. Ehleringer. 1992. Plant adaptation in the Great Basin and Colorado Plateau. Great Basin Naturalist 52:195-215.

Ehleringer, J.R., S.L. Phillips, AND J.P. Comstock. 1992. Seasonal variation in the carbon isotopic composition of desert plants. Functional Ecology 6:396-404.

Farquhar, G.D., J.R. Ehleringer, and K.T. Hubick. 1989. Carbon isotope discrimination and photosynthesis. Annual Review of Plant Physiology and Plant Molecular Biology 40:503-537.

Field, F., AND H.A. MoOney. 1986. The photosynthesisnitrogen relationship in wild plants. Pages 25-55 in T.J. Givnish, editor, On the economy of plant form and function. Cambridge University Press, Cambridge.

Grime, J.P. 1977. Evidence for existence of 3 primary strategies in plants and its relevance to ecological and evolutionary theory. American Naturalist 111:11691194.

Heiser, C.B. 1947. Hybridization between the sunflower species Helianthus annuus and Helianthus petiolaris. Evolution 1:249-262.

JEnnings, D.H. 1976. The effects of sodium chloride on higher plants. Biology Review 51:453-486.

Ludwig, F., R.A. JewitT, AND L.A. Donovan. 2006 Nutrient and water addition effects on day- and nighttime conductance and transpiration in a C-3 desert annual. Oecologia 148:219-225. 
Ludwig, F., D.M. Rosenthal, J.A. Johnston, N. Kane, B.L. Gross, C. Lexer, S.A. DudLey, ET AL. 2004. Selection on leaf ecophysiological traits in a desert hybrid Helianthus species and early-generation hybrids. Evolution 58:2682-2692.

Poorter H., AND C. LeWIS. 1986. Testing differences in relative growth-rate- a method avoiding curve fitting and pairing. Physiologia Plantarum 67:223-226.

Reich, P.B., M.B. Walters, and D.S. Ellsworth. 1997. From tropics to tundra: global convergence in plant functioning. Proceedings of the National Academy of Sciences 94:13730-13734.

RieseberG, L.H. 1991. Homoploid reticulate evolution in Helianthus (Asteraceae): evidence from ribosomal genes. American Journal of Botany 78:1218-1237.

Rieseberg, L.H., O. Raymond, D.M. Rosenthal, Z. LaI, K. Livingstone, T. Nakazato, J.L. Durphy, et al. 2003. Major ecological transitions in wild sunflowers facilitated by hybridization. Science 301:1211-1216.

Rosenthal, D.M., F. Ludwig, And L.A. Donovan. 2005a. Plant responses to an edaphic gradient across an active sand dune/desert boundary in the Great Gasin desert. International Journal of Plant Science 166: 247-255.

Rosenthal, D.M., L.H. Rieseberg, and L.A. Donovan. 2005b. Recreating ancient hybrid species' complex multi-trait phenotypes from early generation synthetic hybrids: three examples using wild sunflowers. American Naturalist 166:26-41.

SMiTH, S.D., AND R.S. NOWAK. 1990. Ecophysiology of plants in the Intermountain lowlands. Pages 179-241 in C.B. Osmond, L.F. Pitelka, and G.M. Hidy, editors, Plant biology of the Basin and Range. SpringerVerlag, Berlin.

Wang, W., B. Vincour, and A. Altman. 2003. Plant responses to drought, salinity, and extreme temperatures: toward genetic engineering for stress tolerance. Planta 218:1-14.

Received 14 Novemeber 2005 Accepted 27 March 2006 